Nigeria Journal of Pure and Applied Physics

Vol. 10(1), 16 - 19, 2020

OPhysics Department, Federal University of Technology Akure

DOI: $10.4314 /$ njpap.v10i1.4

\title{
Characterization of magnetic field horizontal component in selected stations along the $210^{\circ} \mathrm{MM}$
}

\author{
A. Idowu ${ }^{\dagger}$, A. Adimula \\ Department of Physics, University of Ilorin, Ilorin, Nigeria \\ †Corresponding Author’s Email: dayor_id@yahoo.co.uk
}

\begin{abstract}
Characterizing the magnetic field horizontal component $(\mathrm{H})$ variability helps to better accommodate the irregular fluctuations in the electron/ion density of the ionosphere for mitigating short-wave radio communication and Global Navigation Satellite Systems (GNSS) disruptions. This study employed three year data (2007-2009) from Magnetic Data Acquisition System (MAGDAS) facilities at six (6) observatories along the $210^{\circ}$ magnetic meridian (MM) for investigating hourly, seasonal and annual variations in the horizontal component of the Earth's magnetic field. The baseline value of $\mathrm{H}$ was computed from its average value near local midnight hours between 2400 and 0100 local time (LT) and subtracted from other hours value for the hourly variation; while the monthly and annual averages were computed for seasonal and yearly analysis respectively. Results indicates that maximum values of Sq are recorded in equinoctial season with an annual peak value of $70.96 \mathrm{nT}$ for year 2009 recorded at Langkawi (LKW) as against the lowest peak value of $27.45 \mathrm{nT}$ recorded in Cooktown (CKT) at 1300LT.
\end{abstract}

Keywords: Magnetic field, horizontal component, solar quiet, seasonal variation, solar equinox

\section{INTRODUCTION}

The ionosphere is electrically conducting as a result of the partly ionized plasma generated by photoionization as a result of solar radiation, which is the major source of solar quiet $(\mathrm{Sq})$ current. Sq variations occur in the E-region in the ionosphere and can be determined by magnetic records of dynamo action on magnetically quiet days [1].

The midday eastward polarization field generated by global scale dynamo action gives rise to downward hall current at the magnetic dip equator. A strong vertical polarization field is set up which opposes the downward flow of current due to the presence of non-conducting boundaries. This field in turn gives to the intense Hall current which Chapman [1] named the Equatorial Electrojet $(\mathrm{EEJ})$. The equatorial electrojet (EEJ) is a narrow band of intense electric current flowing eastward at 100-120 km altitude within $\pm 3^{\circ}$ latitude of the geomagnetic dip equator in the ionosphere.

Chapman [1], Richmond [2] and Onwumechili [3] observed that the daily variation of geomagnetic field component at the equatorial station is due to the superimposition of the $\mathrm{Sq}$ current and the EEJ current flowing eastward at the lower altitude. Mayaud [4] concluded that if Sq and EEJ currents are flowing opposite to one another such that the westward EEJ current exceeds the global eastward Sq current it is called Counter Electrojet $(\mathrm{CEJ})$. It has been observed that the geomagnetic field intensity vary from one sector to another within the equatorial zone. Fang et al. [5] found that the diurnal ranges of $\mathrm{H}$ at the stations near the equator peaks around the dip equator. The magnitude of Sq was dependent on local time and the strength of Sq current is enhanced at the dip equator $[6-8]$. They observed that the time of maximum $\mathrm{SqH}$ around the equatorial region varies from 1000-1200 Local
Time (LT). Onwumechili [3] concluded that maximum variability of $\mathrm{SqH}$ at low latitudes is more frequent at 1100LT during low solar active period [9]. Okeke et al. [10] observed that smaller $\mathrm{SqH}$ variability occur during the night time hour (when there are no solar activities and suggested that the variablility are from sources different from the ionospheric sources (non-ionospheric sources) like magnetospheric and ring currents). Rastogi et al. [9] reported that at the equatorial station, a clearer semiannual and equinoctial maximum are observed from the annual and seasonal variations, respectively. Chandra et al. [11] attributed equinoctial maximum to the more intense EEJ, which is narrower at the equinoxes. Onwumechili et al. [12] studied the geomagnetic field variation of $\mathrm{SqH}$ at India station, a low latitude sector. They observed maximum magnitude of $\mathrm{SqH}$ during equinoctial months and lowest magnitudes of $\mathrm{SqH}$ at noon hour during $\mathbf{J}$ season which indicates a semi-annual variability is in the range of the $\mathrm{SqH}$ seasonal variation that depicts characteristics of EEJ.

\section{MATERIALS AND METHODS}

Three year data (2007-2009) from Magnetic Data Acquisition System (MAGDAS) facilities for six (6) observatories were used for the study. Five (5) most magnetically quiet days from the Internationally Quiet Day (IQD) in each month for the year 2009 were selected according to the classification of planetary magnetic index, $\mathrm{Kp}$. The baseline value of $\mathrm{H}\left(\mathrm{H}_{0}\right)$ was calculated as the average value of $\mathrm{H}$ component near local midnight between $2400 \mathrm{LT}$ and $0100 \mathrm{LT}$.

$H_{o}=\frac{H_{2400}+H_{2300}+H_{0100}+H_{0200}}{4}$ 


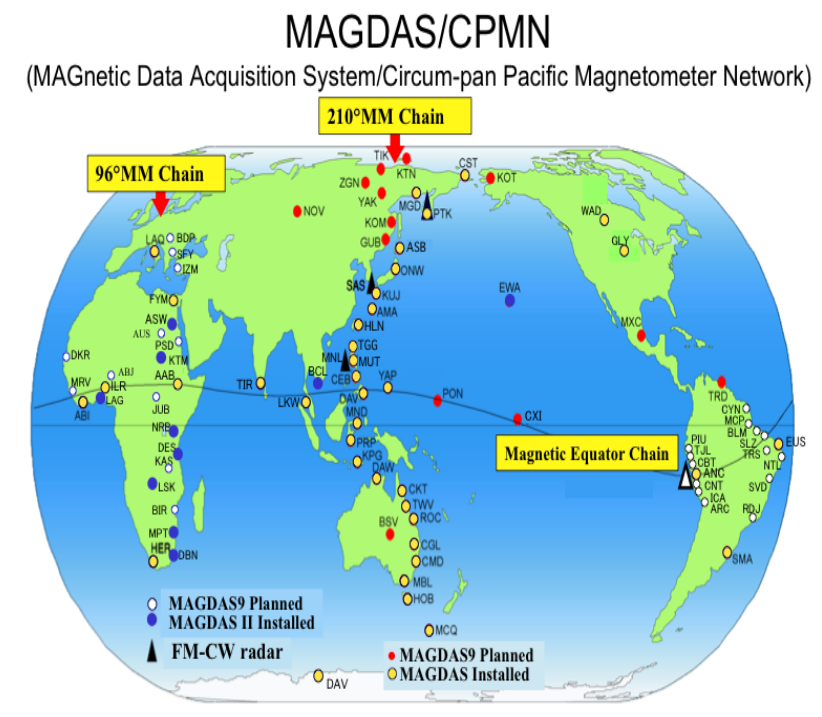

Fig. 1. A global network of MAGDAS magnetometers.

where $\mathrm{H}_{2400}, \mathrm{H}_{2300}, \mathrm{H}_{0100}, \mathrm{H}_{0200}$ represent the hourly values of $\mathrm{H}$ at 24, 23, 02 \& 01 hours LT, respectively. The midnight baseline values were subtracted from the hourly values to get the hourly departures from the midnight for a particular day. Thus:

$d H=H_{t}-H_{o}$

where $\mathrm{t}=1$ to $24, H_{t}$ is hourly values of magnetic element $\mathrm{H}$, $\mathrm{dH}$ gives the measure of the hourly amplitude of the variation of horizontal component of the earth magnetic field $\mathrm{H}$ i.e SqH. Figure 1 shows the global network of MAGDAS magnetometers and Table 1 shows the coordinates of stations used in the study. The seasonal variation was studied by grouping the months into four seasons; December (November, December, January), March Equinox (February, March, April), June Solstice (May, June, July), September Equinox (August, September, October). Each season is estimated by averaging the monthly values on each hour under a particular season while annual variation was examined by averaging monthly values of $\mathrm{dH}$ for the whole year under consideration.

\section{RESULTS AND DISCUSSION}

\subsection{Seasonal variation}

Figure 2a-c shows seasonal variation of $\mathrm{dH}$ at various stations. From the figures, it was observed that seasonal variation was higher in stations closer to the magnetic equator compared to stations located away from equator in all the seasons. Equinoctial season also have higher values compared to solstice period. For instance, YAP recorded maximum values of 84.89 nT in March equinox and minimum value of $70.99 \mathrm{nT}$ in June solstice. Similarly, in March equinox, DAV showed a maximum variation of 82.39 $\mathrm{nT}$ with least variation in (June and December) solstice with values of $54.19 \mathrm{nT}$ and $65.91 \mathrm{nT}$ respectively. LKW displayed maximum value of 75.89 nT (March equinox) with least variation of $43.92 \mathrm{nT}$ in June solstice. Variation of $\mathrm{SqH}$ in CKT recorded maximum value of $30.4 \mathrm{nT}$ in March Equinox and minimum of $21.53 \mathrm{nT}$ in June solstice. The range value of seasonal variation in March equinox for stations investigated is $54.49 \mathrm{nT}, 49.46 \mathrm{nT}$ in June solstice and $39.31 \mathrm{nT}$ in December solstice.

In this research work, it could be seen that maximum values of $\mathrm{Sq}$ are recorded in equinoctial season. The highest peak of $\mathrm{Sq}$ recorded during the equinox could be attributed to enhanced equatorial electron density which increases the electrical conductivity when the sun is overhead at the equinox in addition to changes in corresponding electric field [13]. The seasonal change could be attributed to a seasonal shift in the mean position of Sq current system of

Table. 1. The geographic and geomagnetic coordinates of the stations to be used in the study.

\begin{tabular}{|c|c|c|c|c|c|c}
\hline STATION & STATION & COUNTRY & GEOGRAPHIC & GEOGRAPHIC & GEOMAGNETIC & GEOMAGNETIC \\
NAME & CODE & & LATITUDE & LONGITUDE & LATITUDE & LONGITUDE \\
\hline Cooktown & CKT & Australia & -15.48 & 145.25 & -24.62 & 218.38 \\
\hline Davao & DAV & Philippine & 7.00 & 125.40 & -1.20 & 196.54 \\
\hline Langkawi & LKW & Malaysia & 6.30 & 99.78 & -2.32 & 171.29 \\
\hline Yap island & YAP & Fsm & 9.50 & 138.08 & 1.49 & 209.06 \\
\hline
\end{tabular}



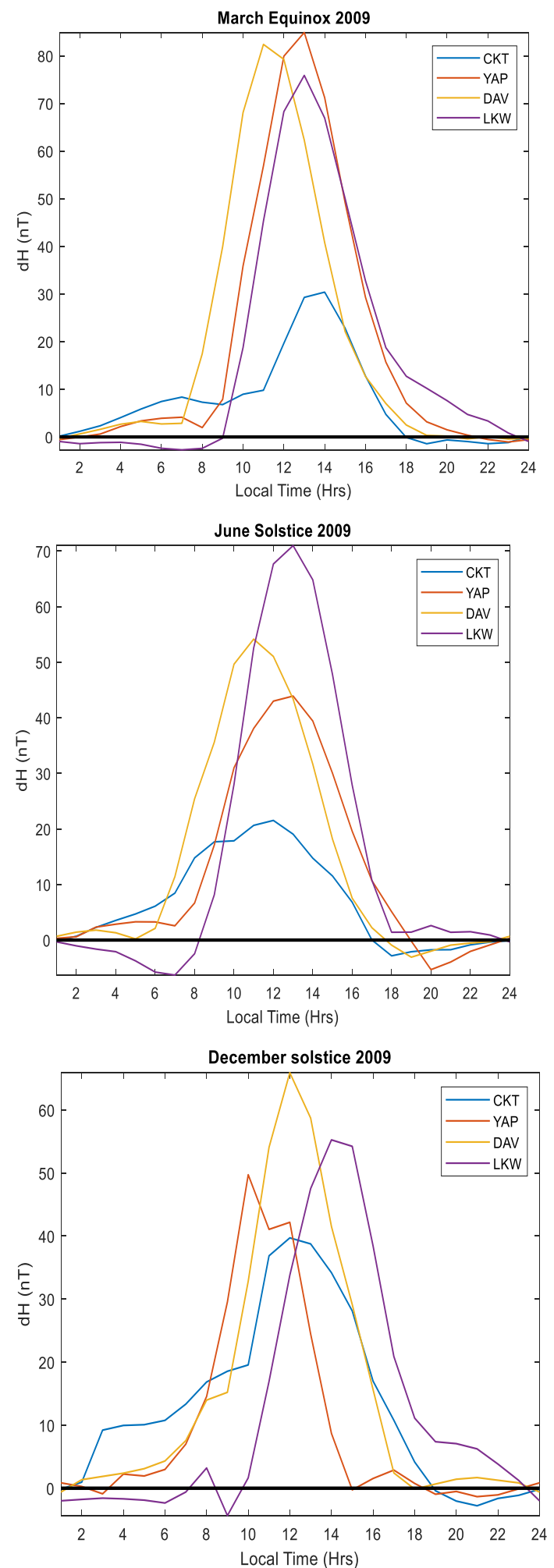

Fig. 2. Seasonal variation of $\mathrm{dH}$ at the four stations.

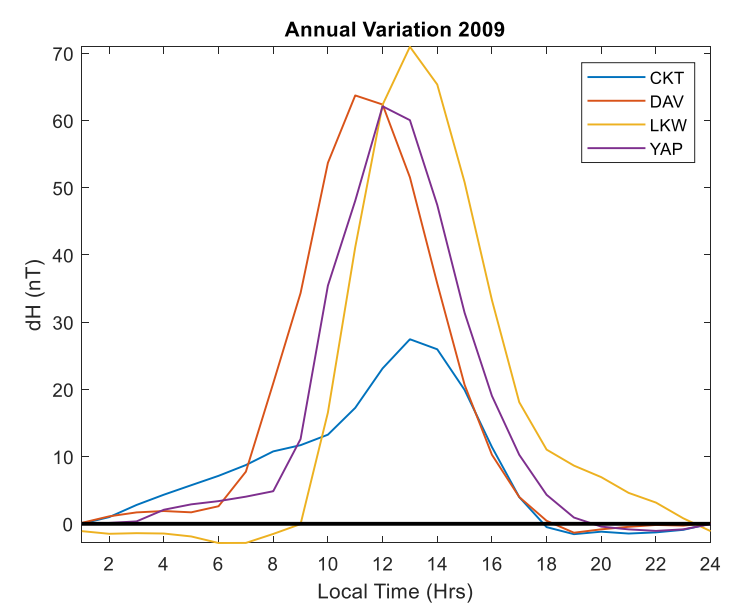

Fig. 3. Annual variation of $\mathrm{dH}$ at the four stations.

the ionospheric electrojet [14]. The electrodynamic effect of local winds can also account for seasonal variability. The seasonal dependence of the solar zenith angle may contribute to the maximum value of $\mathrm{SqH}$ recorded in this work. Higher values of $\mathrm{SqH}$ in equinoctial season have been observed in seasonal variation studies by Chandra et al. [15], Rabiu et al. [8] and Rastogi [9].

\subsection{Annual variation}

. The annual variation of horizontal component of magnetic field for year 2009 is shown in Figure 3. The highest peak value of $70.96 \mathrm{nT}$ recorded at Langkawi (LKW) and the lowest peak value of $27.45 \mathrm{nT}$ in CKT at 1300LT, this present a range value of $46.51 \mathrm{nT}$ for the year. Davao (DAV) presented a value of $63.72 \mathrm{nT}$ at $1100 \mathrm{LT}$ while Yap Island (YAP) recorded a value of $62.11 \mathrm{nT}$ at 1200LT. Generally, peak values of the variation of $\mathrm{dH}$ presented similar trend for both seasonal and annual variation in the year under study.

\section{CONCLUSION}

From the above study, it could be deduced that the horizontal component of the magnetic field in the stations examined exhibits latitudinal variations as the position of the stations affects the magnetic field intensity recorded. The closer the stations are to the magnetic equator, the higher the magnetic field intensity recorded in the station. The variability of the ionospheric processes and physical structure such as conductivity and wind structure are responsible for the sq variation. Also, the nighttime variations observed when there is no solar activity may be as a result of the variability of nighttime distant currents.

\section{REFERENCES}

[1] Chapman, S. (1951). The equatorial electrojet as detected from the abnormal electric current distribution above Huancayo, peru, and elsewhere. Archiv for 
Meteorologie, Geophysik und Bioklimatologie, Serie A, 4(1):368-390. https://doi.org/10.1007/BF02246814

[2] Richmond, A. D. (1974), The computation of magnetic effects of fieldaligned magnetospheric currents, J. Atmos. Terr. Phys., 36, 245 - 252. https://doi.org/10.1016/00219169(74)90044-0

[3] Onwumechilli CA. The Equatorial Electrojet. Gordon \& Breach, Netherlands.1997;627.

[4] Mayaud, P. N. (1977). The equatorial counter electrojet. A review of its geomagnetic aspects. J. Atmos. Terr. Phys. 39: $\quad 1055-1070 . \quad$ https://doi.org/10.1016/00219169(77)90014-9

[5] Fang, T.-W., Richmond, A., Liu, J.-Y., Maute, A., Lin, C.-H., Chen, C.-H., \& Harper, B. (2008). Model simulation of the equatorial electrojet in the Peruvian and Philippine sectors. Journal of Atmospheric and Solar-Terrestrial Physics, 70(17):2203-2211

https://doi.org/10.1016/j.jastp.2008.04.021

[6] Bartels, J and Johnson, H. (1940). Geomagnetic tides in horizontal intensity at Huancayo. J. Geophys. 45, 264-308. https://doi.org/10.1029/TE045i003p00269

[7] Onwumechili, C. A. (1989). Study of the return current of the equatorial electrojet. J. Geomag. Geoelectr., 44:1 https://doi.org/10.5636/jgg.44.1

[8] Rabiu AB, Mamukuyomi AI, Joshua EO (2007). Variability of equatorial ionosphere inferred from geomagnetic field measurements. Bull. Astr. Soc. India.
2007;35:607-618.

[9] Rastogi, R. G. (1994). Westward equatorial electrojet during daytime hours. Journal of geophysical research, 79(10), 1503-1512. $\quad$ https://doi.org/10.1029/JA079 i010p01503

[10] Okeke, F.N., Onwumechili, C.A., \& Rabiu, A.B. (1998). Day-to-day Variability of Geomagnetic Hourly Amplitudes at Low Latitude. Geophys. J. int., 134, 484-500. https://doi.org/10.1046/j.1365-246x.1998.00564.x

[11] Chandra H, Sinha HSS, Rastogi RG. (2000) Equatorial electrojet studies from rocket and ground measurements. Earth Planets Space. 2000;52:111-120. https://doi.org/10.1186/BF03351619

[12] Onwumechili CA. In: Eds. Matsushuita S. and Campbell, W. H. Physics of Geomagnetic Phenomena. Academic press, New York. 1967;1:425-507. https://doi.org/10.1016/B978-0-12-480301-5.50014-8

[13] Adimula I.A. Rabiu, Yumoto, K., the MAGDAS group (2011). Geomagnetic Field Variation for some Equatorial Electrojet Stations. Sun and geosphere, 2011; 6(2): 45-49.

[14] Hutton, R. (1962). The solar and lunar daily variations of Earth currents near the magnetic equator. Journal of Atmospheric and Terrestrial Physics, 24(8), 673-680.

[15] Rastogi, R. G., Chandra, H. \& Chakravarty, S. C. (1971). The disappearance of equatorial Es and reversal of electrojet current, Proc. Indian Acad. Sci., 74: 62-67. https://doi.org/10.1007/BF03047392 